LETTERS

\title{
Prevention of glucocorticoid osteoporosis: a consensus document of the Dutch Society for Rheumatology
}

\section{P P Geusens, R N J de Niijs, W F Lems, R F J M Laan, A Struijs, T P van Staa, J W J Bij|sma}

$\mathrm{H}$ ugeberg et al recently published clinical decision rules to identify patients with rheumatoid arthritis (RA) at risk for osteoporosis. ${ }^{1}$ Included were patients treated with glucocorticoids, a subject that has been for a long time the interest of rheumatologists. ${ }^{2-4}$

For example, the Dutch Society for Rheumatology has recently published guidelines for the prevention of glucocorticoid induced osteoporosis (GIOP). ${ }^{5}$ This document was prepared by a group of rheumatologists of the society and other experts to mark the occasion of the publication of the 3rd Osteoporosis Guideline, (the "CBO consensus") which was, in turn, prepared at the request of the Dutch authorities by a multidisciplinary group who examined evidence based medicine. ${ }^{\circ}$

Figure 1 is a stream diagram showing the diagnostic and therapeutic steps in making decisions for the prevention of GIOP. ${ }^{5}$ Factors that influence this decision include the dose of glucocorticoids and the presence of other risk factors such as age, sex, previous fracture, and bone mineral density (BMD). The main message is that treatment with bisphosphonates should be started immediately in patients at high risk (high dose of glucocorticoids, prevalent fracture, postmenopausal women, and elderly men).

The recommendations cover some uncertainties. Firstly, it is unclear what is the threshold value of BMD below which prevention is indicated if the intake of glucocorticoids is $<7.5 \mathrm{mg}$ prednisone equivalents/day in the absence of other risk factors. The $\mathrm{CBO}$ consensus suggested a $\mathrm{T}$ score $<-2.5$ or a $\mathrm{Z}$ score $<-1 .{ }^{6}$ However, other groups have suggested different thresholds. The UK consensus group suggested a $\mathrm{T}$ score $<-1.5^{7}$ and the American College of Rheumatology suggested a $\mathrm{T}$ score $<-1$. $^{3}$ The main reason for the absence of consensus is the uncertainty that the risk for osteoporosis is increased in a low risk group treated with low dose glucocorticoids, that fractures can be prevented in this group and, perhaps most relevant, that the fracture threshold is altered in GIOP. ${ }^{8}$ Indeed, bone loss is limited in patients chronically treated with low dose glucocorticoids if calcium and vitamin D supplements are given. ${ }^{9}$

Secondly, it is still unclear if these patients should have an $x$ ray examination of the spine to document vertebral deformities. Although only one in three vertebral deformities is accompanied by acute symptoms of fractures, it has been recently shown that non-clinically manifest vertebral deformities also result in increased morbidity and an increased risk for new fractures. ${ }^{10}{ }^{11}$ Introducing a new risk factor is a reason for increasing awareness: starting glucocorticoid treatment should be accompanied by treatment with bisphosphonates in high risk patients and by dual energy $x$ ray absorptiometry (DXA) measurement in others.

Thirdly, specific risk factors of bone loss in conditions such as RA were not considered. Accelerated bone loss has been documented in patients with RA with high disease activity, ${ }^{12}$ immobility, and low body weight. ${ }^{13}$ However, no studies are available on the prevention of osteoporosis in patients with RA with these risk factors, and, thus, this information was lacking in the guidelines.

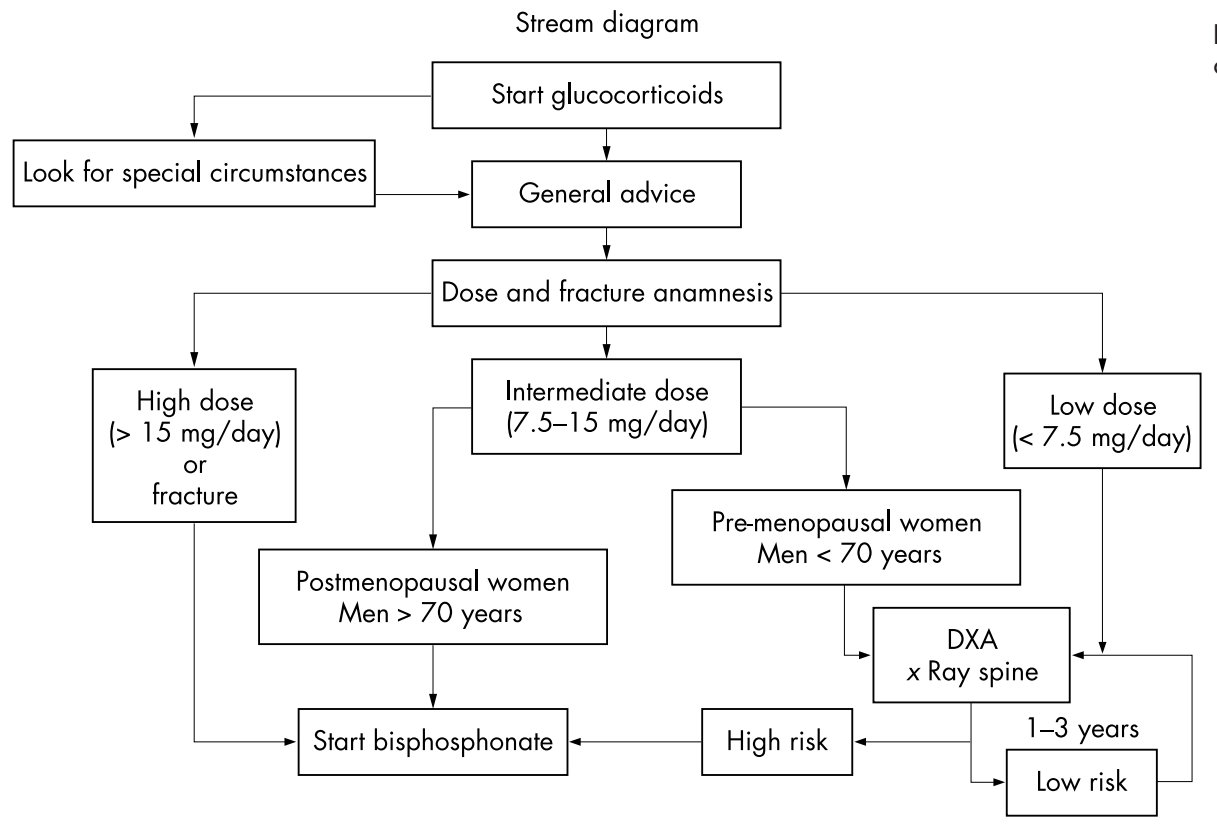

Figure 1 Stream diagram for osteoporosis prevention in GIOP. 
In conclusion, the guidelines on the prevention of GIOP, which have been approved by the Dutch Society for Rheumatology, should increase awareness about patients at high risk. The publication by Haugeberg et al draws our attention to patients with RA who are not treated with glucocorticoids who perhaps also should be a target for prevention of bone loss and osteoporosis. This proposal needs to be fully explored in future studies. Thus, guidelines may disclose not only our knowledge in specific clinical situations but also may open up areas for new research.

\section{Authors' affiliations \\ P P Geusens, Academisch Ziekenhuis Maastricht, The Netherlands and Limburgs Universitair Centrum, Diepenbeek, Belgium \\ R N J de Nijs, J W J Bijlsma, Universitair Medisch Centrum Utrecht, The Netherlands \\ W F Lems, Vrije Universiteit Medisch Centrum en Slotervaartziekenhuis, Amsterdam, The Netherlands \\ R F J M Laan, Academisch Ziekenhuis Nijmegen, The Netherlands A Struijs, Erasmus Medical Centre Rotterdam, The Netherlands T P van Staa, Procter and Gamble, UK}

Correspondence to: Professor P Geusens, Department of Rheumatology University Hospital Maastricht, 6202 AZ Maastricht, The Netherlands; piet.geusens@ping.be

Accepted 19 May 2003

\section{REFERENCES}

1 Haugeberg G, Orstavik RE, Uhlig T, Falch JA, Halse J, Kvien TK. Clinical decision rules in rheumatoid arthritis: do they identify patients at high risk for osteoporosis? Testing clinical criteria in a population based cohort of patients with rheumatoid arthritis recruited from the Oslo Rheumatoid Arthritis Register. Ann Rheum Dis 2002;61:1085-9.

2 Recommendations for the prevention and treatment of glucocorticoid-induced osteoporosis. American College of Rheumatology Task Force on Osteoporosis Guidelines. Arthritis Rheum 1996;39:1791-801.

3 Recommendations for the prevention and treatment of glucocorticoid-induced osteoporosis: 2001 update. American College of Rheumatology Ad Hoc Committee on Glucocorticoid-Induced Osteoporosis. Arthritis Rheum 2001:44:1496-503.

4 de Niijs RN, Jacobs JW, Biilsma JW, Lems WF, Laan RF, Houben HH, et al. Prevalence of vertebral deformities and symptomatic vertebral fractures in corticosteroid treated patients with rheumatoid arthritis. Rheumatology (Oxford) 2001;40:1375-83.

5 Niijs RNJ de, Lems WF, Laan RFJM, Struijs A, Staa TP van, Geusens P, et al. Ronde tafelbijeenkomst: preventie en behandeling van glucocorticosteroïd geïnduceerde osteoporose. Ned Tiidschr voor Reumatologie 2002;1:12-19.

6 Pols HA, Wittenberg J. CBO guideline 'Osteoporosis' (second revision). Ned Tiidschr Geneeskd 2002;146:1359-63.

7 Eastell R, Reid DM, Compston J, Cooper C, Fogelman I, Francis RM, et al. A UK consensus group on management of glucocorticoid-induced osteoporosis: an update. J Intern Med 1998;244:271-92.

8 van Staa TP, Leufkens HG, Abenhaim L, Zhang B, Cooper C. Oral corticosteroids and fracture risk. J Bone Miner Res 2000;15:993-1000.

9 van Everdingen AA, Jacobs JW, Siewertsz Van Reesema DR, Bijlsma JW. Low-dose prednisone therapy for patients with early active rheumatoid arthritis: clinical efficacy, disease-modifying properties, and side effects: a randomized, double-blind, placebo-controlled clinical trial. Ann Intern Med 2002;136:1-12.

10 Nevitt MC, Ettinger B, Black DM, Stone K, Jamal SA, Ensrud K, et al. The association of radiographically detected vertebral fractures with back pain and function: a prospective study. Ann Intern Med 1998;128:793-800.

11 Black DM, Arden NK, Palermo L, Pearson J, Cummings SR. Prevalent vertebral deformities predict hip fractures and new vertebral deformities but not wrist fractures. J Bone Miner Res 1999;14:821-8.

12 Gough AK, Lilley J, Eyre S, Holder RL, Emery P. Generalised bone loss in patients with early rheumatoid arthritis. Lancet 1994;344:23-7.

13 Haugeberg G, Uhlig T, Falch JA, Halse JI, Kvien TK. Reduced bone mineral density in male rheumatoid arthritis patients: frequencies and associations with demographic and disease variables in ninety-four patients in the Oslo County Rheumatoid Arthritis Register. Arthritis Rheum 2000;43:2776-84.

\title{
Does long term treatment with azathioprine predispose to malignancy and death in patients with systemic lupus erythematosus?
}

\author{
P Nero, A Rahman, D A Isenberg
}

Ann Rheum Dis 2004;63:325-326. doi: 10.1136/ard.2002.005371

$\mathrm{T}$ he treatment of patients with rheumatic diseases with second line agents has expanded in the past three decades. However, such drugs have been linked with the development of malignancy, particularly in patients with rheumatoid arthritis. ${ }^{1}$ Azathioprine is used to treat patients with systemic lupus erythematosus (SLE) with renal disease, or as a steroid-sparing agent. ${ }^{2}$ We have assessed the risk that azathioprine treatment predisposes to the development of malignancies and death in patients with SLE.

We carefully reviewed the case notes of 358 patients with SLE receiving long term follow up in the Lupus Clinic at University College London, between 1978 and 2002, and assessed their treatment. Three hundred and twenty six (91.1\%) patients were female and $32(8.9 \%)$ male. One hundred and forty eight $(41.3 \%)$ were treated at any time with azathioprine, while $210(58.7 \%)$ never used this second line agent. The mean (SD) ages of the users and non-users were similar (40.5 (12.7) $v 45.3$ (13.2), respectively, which is not significant by $\chi^{2}$ test with $95 \%$ confidence intervals). The mean (SD) duration of azathioprine treatment was 3.8 (3.9) years (minimum of 6 months and maximum of 18 years). Most patients are alive $(83.2 \%)$ and only a minority were lost to follow up $(3.1 \%)$. Forty nine $(13.7 \%)$ of our patients have died: $27 / 148(18 \%)$ had received azathioprine and 22/210 $(10 \%)$ had not. Eight of our patients prescribed azathioprine developed a malignancy (none had a lymphoma), whereas 14 not given azathioprine have done so (three had lymphomas: one non-Hodgkin and two Hodgkin). These differences are not statistically significant $\left(\chi^{2}\right.$ test). However, the number of deaths in the azathioprine group which is almost double that in the other group does raise concerns, although it may simply be identifying a subgroup with more serious disease.

Table 1 shows the number of malignancies and death in patients with SLE treated with azathioprine, according to the duration of treatment.

Five of the patients who died were receiving azathioprine for $<1$ year, 10 for between 1 and 4 years, 11 for between 5 and 9 years, and 1 for $>10$ years. Five patients who developed malignancy were receiving azathioprine for 
Table 1 Number of deaths and malignancy in patients with SLE treated with azathioprine

\begin{tabular}{lllll}
\hline $\begin{array}{l}\text { Azathioprine } \\
\text { (years of } \\
\text { treatment) }\end{array}$ & $\mathbf{n}$ & $\begin{array}{l}\text { Died } \\
\text { No }(\%)\end{array}$ & $\begin{array}{l}\text { Lost to follow } \\
\text { up } \\
\text { No }(\%)\end{array}$ & $\begin{array}{l}\text { Malignancy } \\
\text { No (\%) }\end{array}$ \\
\hline$<1$ & 38 & $5(13)$ & 0 & 0 \\
$1-4$ & 55 & $10(18)$ & $2(4)$ & $5(9)$ \\
$5-9$ & 40 & $11(28)$ & 0 & $3(8)$ \\
$\geqslant 10$ & 15 & $1(7)$ & 0 & 0 \\
\hline
\end{tabular}

between 1 and 4 years and 3 for between 5 and 9 years. The two patients lost to follow up had been receiving azathioprine treatment for 3 and 4 years at that time.

We have been unable to locate any publications examining azathioprine related complications in the treatment of patients with SLE. In rheumatoid arthritis and in Sjögren's syndrome, however, it has been linked with lymphoma development. ${ }^{134}$

We conclude that although azathioprine seems to be a safe second line agent for the treatment of patients with SLE larger and longer term studies are needed to confirm these findings.

\section{Authors' affiliations}

P Nero, Unidade de Reumatologia, Hospital de Egas Moniz, Lisboa, Portugal

A Rahman, D A Isenberg, Centre for Rheumatology, Department of

Medicine, University College London, London, UK

Correspondence to: Dr P Nero, Hospital de Egas Moniz, R. da Junqueira, 126 Lisboa 1349-019, Portugal ; patricianero@hotmail.com

Accepted 20 May 2003

\section{Bone mineral density in patients with systemic sclerosis B Frediani, F Baldi, P Falsetti, C Acciai, G Filippou, A Spreafico, F Chellini, C Capperucci, P Filipponi, M Galeazzi, R Marcolongo}

G eneralised radiological osteopenia has been seen to occur in a significant percentage of patients with systemic sclerosis (SSc). ${ }^{12}$ Bone mineral content was found to be reduced at the radius, ${ }^{3-5}$ lumbar spine, and the total body. ${ }^{5}$ No data are available on quantitative ultrasound (QUS) evaluation of bone in patients with SSc.

\section{PATIENTS AND METHODS}

In this study, bone mineral density (BMD) and stiffness index (SI) were measured in patients with SSc not treated with steroids to investigate the presence of systemic osteoporosis.

Forty seven women (mean age 53.9 years (range 32-77)) affected with SSc were investigated: 20 were premenopausal (preSSc) and 27 postmenopausal (postSSc). All the patients satisfied the preliminary American Rheumatology Association criteria indicated in the classification of progressive SSc.

The control group consisted of 50 healthy female subjects: 23 premenopausal (prenorm) and 27 postmenopausal (postnorm). The exclusion criteria were treatment with corticosteroids, immunosuppressant drugs, hormone replacement therapy, thyroxine, and bone regulating drugs and the presence of demineralising diseases.

A detailed history was taken of each patient, with particular reference to age, menopausal status, disease duration, current or previous treatments, and current or previous diseases; their height and weight were measured and related by the body mass index ratio. There were no significant differences between groups. The following serological markers were determined: antinuclear antibodies, anticentromere antibodies, anti-extractable nuclear antigen, including anti-Scl70, -Sm, -RNP, -SSB, -SSA, and Jo- 1 .

Examinations were also carried out to determine the extent of any internal organ involvement. The patients were divided into three groups based on the extent of cutaneous involvement ${ }^{6}$ : limited, intermediate, and diffuse. BMD (total body, lumbar spine, and femur neck) was evaluated by fan beam $x$ ray Lunar Expert, version 1.72. The SI (derived from broadband ultrasound absorptiometry and speed of sound) was evaluated by quantitative ultrasonometry of the heel using the Lunar Achilles Plus. T scores (the difference between the BMD of the patients and that of young healthy adults corrected for the standard deviation) were used in dual $x$ ray absorptiometry and QUS.

\section{RESULTS}

The results of this study show that bone mass was reduced in patients with SSc. BMD, expressed in $\mathrm{g} / \mathrm{cm}^{2}$, was significantly less in the SSc subgroups than in controls (lumbar spine BMD: 1.309 prenorm $v 1.159$ preSSc, $\mathrm{p}<0.05 ; 1.193$ postnorm $v 0.952$ postSSc, $\mathrm{p}<0.01$; neck femur BMD: 1.010 prenorm $v 0.938$ preSSc, $\mathrm{p}<0.05 ; 0.904$ postnorm $v 0.816$ postSSc, $\mathrm{p}<0.01$; stiffness: 100.0 prenorm $v 72.0$ preSSc, $\mathrm{p}<0.05 ; 91.0$ postnorm $v 78.2$ postSSc, $\mathrm{p}<0.05)$. $\mathrm{T}$ scores were lower in the SSc subgroups than in controls. The reduction in bone mass was more marked in the lumbar spine and heel. It is known that these two sites are, respectively, partially and completely trabecular. SSc related osteoporosis thus seems to have the typical characteristics of postmenopausal osteoporosis.

Many studies suggest that QUS is useful in investigating bone quality. ${ }^{7}$ In our patients the prevalent impairment of stiffness at the heel also provided an additional indication for the presence of a qualitative alteration in the trabecular microarchitecture

BMD was not significantly different in patients with normal or altered indices of inflammation and in patients with absence or presence of specific autoantibodies. BMD and SI were reduced in women with the diffuse form of skin involvement and in women with one or more internal organs affected (table 1). A previous study reported that bone mass was related to the extent of skin involvement but did not evaluate the extent of visceral involvement. ${ }^{5}$ Many authors 
Table 1 Bone mineral density $\left(\mathrm{g} / \mathrm{cm}^{2}\right)$ in women with SSc categorised according to the extent of disease

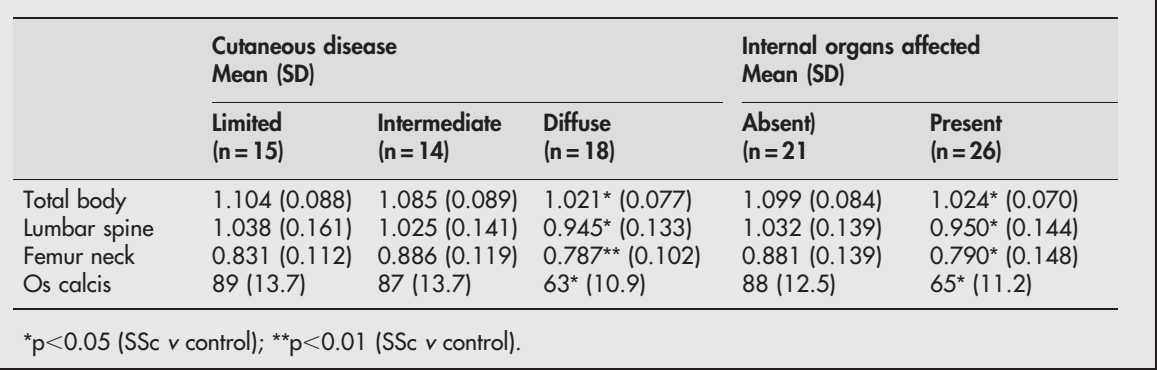

suggest that the extent of skin involvement is directly related to the extent of visceral involvement and to the severity of the disease. $^{8-10}$

In the patients as a whole, a logistical model was prepared in which the presence of osteoporosis (a T score below -2.5) in at least one skeletal site was the dependent variable. In this model the age of the subject, years since menopause, and body mass index were all significantly associated with osteoporosis.

In conclusion our data suggest that bone mass, bone density, and bone quality are altered in patients with SSc with the diffuse form of skin disease and/or at least one internal organ affected.

\section{Authors' affiliations}

B Frediani, F Baldi, P Falsetti, C Acciai, G Filippou, A Spreafico,

F Chellini, C Capperucci, M Galeazzi, R Marcolongo, Institute of

Rheumatology, University of Siena, Italy

P Filipponi, Bone and Mineral Research Unit, University of Perugia, Italy

Correspondence to: Dr B Frediani, Institute of Rheumatology, Policlinico "Le Scotte", Viale Bracci 1, 53100 Siena ltaly;

fredianibruno@tiscalinet.it

Accepted 21 May 2003

\section{REFERENCES}

1 Tuffanelli DL, Winkelmann RK. Systemic sclerorerma. Arch Dermatol 1961;84:49-61.

2 Blocka KLN, Basset LW, Furst DE, Clements PJ, Paulus HE. The arthropathy of advanced progressive systemic sclerosis: a radiographic survey. Arthritis Rheum 1981;24:874-84.

3 Serup J, Hagdrup HK, Tvedegaard E. Bone mineral content in systemic sclerosis measured by photon absorptiometry. Acta Dermatovener 1983;63:235-7

4 La Montagna G, Vatti M, Valentini G, Tirri G. Osteopenia in systemic sclerosis. Evidence of a participating role of earlier menopause. Clin Rheumatol 1991;10:18-22.

5 Di Munno O, Mazzantini M, Massei P, Ferdeghini M, Pitaro N, Latorraca A, et al. Reduced bone mass and normal calcium metabolism in systemic sclerosis with and without calcinosis. Clin Rheumatol 1995: 14:407-12

6 Ferri C, Bernini L, Cecchetti R, Latorraca A, Marotta G, Pasero G, et al. Cutaneous and serological subset of systemic sclerosis. J Rheumatol 1991; 18:1826-32.

7 Prins SH, Jorgensen LV, Hassager C. The role of quantitative ultrasound in the assessment of bone: a review. Clin Physiol 1998;18:3-17.

8 Masi AT. Calssification of systemic sclerosis (scleroderma): relationship of cutaneous subgroups in early disease to outcome and serological reactivity. J Rheumatol 1988:15:894-8.

9 LeRoy EC, Black C, Fleischmajer R, Jablonska S, Krieg T, Medsger TA Jr, et al. Scleroderma (systemic sclerosis): classification, subset and pathogenesis. J Rheumatol 1988;15:202-5.

10 Giordano M, Valentini G, Migliaresi S, Picillo U, Vatti M. Different antibody pattern and different prognoses in patients with scleroderma with various extent of skin sclerosis. J Rheumatol 1986;13:911-16. 